\title{
How Do Population and Urbanization Cause Environmental Degradation in South Asian Countries? A Panel Data Analysis
}

\author{
Noreen Safdar ${ }^{a}$, Shezza Ashraf ${ }^{b}$, Fatima Farooq ${ }^{c}$, Junaid Qadir ${ }^{\text {d }}$ \\ ${ }^{a}$ Assistant Professor, Department of Economics, the Women University Multan, Pakistan \\ E-mail: noreen.safdar@wum.edu.pk \\ ${ }^{\mathrm{b}}$ M.Phil. scholar Department of Economics, the Women University Multan, Pakistan \\ ${ }^{c}$ Assistant Professor, School of Economics, Bahauddin Zakariya University Multan, Pakistan \\ E-mail: fatimafarooq@bzu.edu.pk \\ ${ }^{\mathrm{d}}$ Visiting Lecturer, School of Economics, Bahauddin Zakariya University Multan, Pakistan \\ Email: Junaidkhan.alizai2o@yahoo.com
}

\begin{tabular}{l}
\hline ARTICLE DETAILS \\
\hline History: \\
Accepted 18 Nov 2020 \\
Available Online 31 Dec 2020 \\
\hline Keywords: \\
Economic Growth, Population, \\
Environmental Degradation, \\
PMG, $\mathrm{CO}_{2}$ Emissions
\end{tabular}

JEL Classification: O47, O49, P23

DOI: $10.47067 /$ reads.v6i4.279

\begin{abstract}
The following study shows the economic consequences of population and environmental degradation in selected South Asian Countries for the time period 2000- 2018. Panel cointegration shows the long-run association among population, urbanization, environment and economic growth. By using PMG estimation technique, the results show that environmental degradation has a negative influence on economic growth while the urban population has a progressive impact on economic growth while the total population has a negative impact on economic growth. The results of causality analysis show that there is bidirectional causality among all variables which indicates that population, urbanization, environment and economic growth are causing each other. It is also noticed by the causality analysis that population, urbanization and economic growth are causing environmental degradation in south Asian countries. Further the results show that there is cross-sectional dependency among all variables in selected countries which reveals that all these countries should make collaborative strategies to increase economic growth and to cope up the problem of environmental degradation.
\end{abstract}

(C) 2020 The authors. Published by SPCRD Global Publishing. This is an open access article under the Creative Commons Attribution-

NonCommercial 4.0

Corresponding author's email address: fatimafarooq@bzu.edu.pk

\section{Introduction}

Economic growth, population and environmental degradation are economically interrelated. Economic growth is the foundation of development of any country. Economic growth refers to rise in the manufacturing of capital goods, human capital, technology and labor force with in a country from a different time period spam. Economic progress is also affected by the population. If the population is increasing day by day then economy may be affected because population have positive as well as 


\section{Review of Economics and Development Studies, Vol. 6 (4) 2020, 799 - 809}

negative influence on growth. The population of South Asian countries rises exponentially but the food supply for the population is going to increase by arithmetically. Therefore, these countries are remains poor. Population faces shortage of fundamental necessities for example: clean water, food, sufficient protection, health care and education in South Asian countries. The South Asian countries may also be varied in size, density of population and development.

There are many factors which affect the level of growth such as increase in the production, demographic change (increase in the population), change in the technologies and environmental changes etc. In the South Asian countries such as Bangladesh and Nepal are lies in category of lowincome countries while India, Pakistan and Sri Lanka are lies in the lower middle-income countries.

There are different ways to rise economic growth i.e., efficient use of advanced technologies and rise in the physical capital products such as equipment, vehicles, buildings, tools and machinery etc. Similarly, another way to boost up the economy is to expand the labor force i.e., more labor will produce more output. Finally, human capital is necessary for the growth of economy. Because well aware labor force can produce goods and services by using factors of production effectively although they can use technologies efficiently. The productivity skill of labor is upgraded through training sessions and some practices.

Increase in economic growth may cause of the environmental degradation. Environmental deterioration may be described as the probability of the unprotected surroundings for the entire world. The destruction of the environment usually based on the pollution like water pollution, air pollution and land pollution etc. These issues are harmful for individual's health and for the natural resources.

There are many reasons of the environmental degradation such as: global warming, bad agricultural policies, deforestation, climate change, resource depletion, transportation, unplanned construction, exhaust gases from factories and auto emissions, technological change and chemical effluents. It is clearly identified that any modification and disturbance in the environment is observed as unfavorable and undesirable. Environmental deterioration is sometime due to natural resources and sometime rise by human's activities. Now a days the environmental degradation is caused by the human's extra ordinary behavior towards the natural resources. The continuous growth of technologies and excessive use of natural resources for manufacturing of goods and services are main reasons of environmental degradation. Environmental distortions is caused by economic activities and in return it had unfavorable effects on economy

The present study finds the cause and effect of urbanization, total population and environmental degradation and economic growth. The study differentiates with other studies in existing literature by employing PMG autoregressive distributed lag model (ARDL) to find out short run and long run impact of Population and Urbanization on Environmental Degradation in South Asian Countries

This research work would be important for policy makers concerning these developing countries as it focusses on importance of collaborative development strategy for all developing countries. The existing literature reveals that limited empirical studies were conducted on this issue.

\section{Literature Review}

Alam et al. (2016) studied association amongst $\mathrm{CO}_{2}$ emission, energy use, growth and population growth during 1970-2012. $\mathrm{CO}_{2}$ emission was dependent variable while GDP per capita, energy use and population growth were adopted as independent variables of this study. The analysis used ARDL Bound 


\section{Review of Economics and Development Studies, Vol. 6 (4) 2020, 799 - 809}

Test approach to explain the empirical results. These results displayed that energy use and income consumption had a positive impact on the $\mathrm{CO}_{2}$ emission. With the increase in the population growth, the $\mathrm{CO}_{2}$ emission was increased in some countries although decline in some other countries.

Ahmad and DU (2017) investigated that the energy production and $\mathrm{CO}_{2}$ emission had a major impact on the economy of Iran by taking data from 1971 to 2011. To analyze the relationship between variables, (ARDL) model was adopted. This analysis concluded that there exist the long run association amongst the $\mathrm{CO}_{2}$, GDP per capita, foreign and domestic investment, inflation, population density and agriculture land. This had been shown that $\mathrm{CO} 2$ emission, energy production and domestic investment had a positive and significant influence on economy although foreign investment had positive but insignificant effect on economy in long run comparably inflation and population had negative impact on the GDP per capita.

Belaid and Youssef (2017) explored the association between the environment and the economic growth. Time series data during the year 1980-2012 was used to see the influence of growth, renewable and non-renewable electricity use on the economic degradation. The Unit Root Test, (ARDL) model and Granger Causality Test were used to evaluate this study. The empirical consequences of this analysis declared that long run association existed among the Carbon dioxide emission, renewable electricity use (REC), non-renewable electricity use (NREC) and economic growth. The study concluded that, the renewable electricity use had a beneficial effect on environment while the non-renewable electricity consumption had an injurious influence on environment.

Bakhsh et al. (2017) found the association among FDI, Economic growth, $\mathrm{CO}_{2}$ emissions, and renewable waste in Pakistan. Time series data from 1980-2014 was used in this study. FDI, GDP per capita, human capital, labor, pollutants and capital were the variables of this study. Simultaneous equation model was applied to analyze association among variables. The study concluded that FDI had a negative influence on Carbon Dioxide emissions, Capital and labor had positive impact on GDP, Pollution had negative effect on GDP and FDI had positive impact on capital stock for growth.

Hanif and Santos (2017) explained that the reduction of environmental deterioration and control of population have much importance for the economic stability. The unbalanced panel data during the period 1972-2011 was used in this study. The variables of this study were environmental degradation, economic development, population size and economic stability. This study provided an evidence about Environmental Kuznets Curve hypothesis. The study concluded that the economic development had negative effect on environmental deterioration while population had a positive consequence on environmental degradation.

Miao (2017) examined effective factors of energy use and carbon emissions by urban residential in China. The data for 216 Chinese cities for year 2013 was used for the empirical estimation. The variables of this study were carbon emission, GDP per capita, energy and urban population. The study concluded that population and income level had positive effect on carbon emissions and energy consumption. Transportation had positive impact on vehicle ownership, but fuel price had a negative impact on vehicle ownership. This was suggested that urban strategy and urban design were developed to lessen the $\mathrm{CO}_{2}$ emissions and energy consumption.

Moutinho et al. (2017) explained that the $\mathrm{CO}_{2}$ emissions affected by growth in Spanish and Portuguese. The panel data for 1975-2012 was used in this study. $\mathrm{CO}_{2}$ emission was the dependent variable while energy consumption and gross value added were the independent variables of this study. 


\section{Review of Economics and Development Studies, Vol. 6 (4) 2020, 799 - 809}

The study provided the evidence about the EKC hypothesis. The panel corrected standard errors (PCSE) was used to estimate the EKC. It's concluded that the increase in gross value added would increase the $\mathrm{CO}_{2}$ emission until it reached at GDP level, it showed the positive relationship among the GVA and $\mathrm{CO}_{2}$ emissions.

Yeh and Liao (2017) examined association among carbon emission, population size and the economic development in Taiwan from 1990-2014. The (STIRPAT) model was used to study the consequences of both population and economic expansion. The study concluded that the GDP had the negative impact on the $\mathrm{CO}_{2}$ and population had positive impact on $\mathrm{CO}_{2}$.

Acheampong (2018) found the association among GDP per capita, energy usage and Carbon dioxide emission. The panel data from 1990-2014 was applied in this study. Economic growth, energy use and Carbon dioxide emission were variables assumed in this article. The panel vector auto regressive methodology was used to see the impact of variables. The study has shown no effect of GDP on Carbon dioxide emissions at regional level, negative impact of GDP on $\mathrm{CO}_{2}$ emission at worldwide and Caribbean-Latin America, energy use had a positive influence on GDP at sub-Saharan Africa, use had a negative influence on GDP at international level and energy use had a positive effect on Carbon dioxide emissions at MENA (middle, east, north and Africa).

Botetzagias et al. (2018) investigated that the economic crises ruined the environmental performance. The data from the year 2000-2015 was used to see the troika ${ }^{1}$ effect on environment at the time of economic depression and the formal time. In this study Hierarchical linear multilevel (HLM) was used to check the link between environmental performance and the economic crises. The variables of this study were GDP per capita, GHG emission, environmental taxes, troika effect and renewable energy share and energy intensity. This concluded that the economic downturn had harmful effect on the EU country's environment. Similarly, Troika effect had insignificant and positive impact on the environment.

Charfedine et al. (2018) explored the linkage amongst environmental quality and economic growth of Qatar's economy. The Time Series data against 1970-2014 was used. The variables of this study were GDP per capita, capital per capita, labor force, energy use per capita, electric power consumption per capita, urbanization rate and trade openness. Unit root test, VECM Granger causality test and (ARDL) bound test were used to analyze the relationship among variables. The study concluded that the labor was positively correlated with real GDP while energy use had negative and unfavorable influence on the economic growth. Electricity power, urbanization and trade openness had an optimistic impact on GDP per capita.

Chenn et al. (2018) studied that the energy consumption, growth, energy intensity and urbanization had the influence on the $\mathrm{PM}_{2.5}$ Concentrations in different nations internationally. The balanced panel data was used against 1998-2018 for 141 countries which was different on their income level. The Granger causality test, VECM model, balanced co-integration and panel unit root test were adopted to empirically analyze relationship between $\mathrm{PM}_{2.5}$ concentration and GDP per capita etc. This study resolved that GDP per capita, energy consumption structure and urbanization had unpropitious impact on the $\mathrm{PM}_{2.5}$ concentration. While energy intensity had a negative impact on $\mathrm{PM}_{2.5}$ concentration.

1 A small grouping of three persons functioning together, particularly in an administrative or managerial capacity. 


\section{Review of Economics and Development Studies, Vol. 6 (4) 2020, 799 - 809}

Gilmont et al. (2018) examined association amongst rainfall and economic expansion in India. Time series data of 1961 -2012 was used to see the impact of rainfall on the GDP per capita. The variables were rainfall, GDP per capita, underground water, Irrigation, agricultural land and water security. OLS regression methodology was adopted to analyze influence of rainfall on economic growth. This study concluded that rainfall variation had a negative impact on environmental progress while continually correlated economic growth and rainfall deviation through the entire accessible record.

Wang et al. (2018) found that the urbanization and industrialization played a vital part in economic growth in India and China for years 1980-2014. The variables of this analysis were GDP per capita, urbanization, $\mathrm{CO}_{2}$ emission and industrialization. The Tapio decoupling model used to check the decoupling status while the co integration test and unit root test was used to estimate effects of variables. The study concluded that China performed weak decoupling of GDP per capita. In China the biggest driver of decoupling was urbanization, GDP and urbanization but in India the main driver of decoupling was carbon emission intensity.

Adzawla et al. (2019) examined that the emission of greenhouse gases affected the economic growth of sub-Sahara Africa. The panel data over the period 1970 - 2012 was used to examine relationship among GHG emission and economic growth. A vector auto regressive model and OLS regression model were used to estimate the association among variables. The link among $\mathrm{CO}_{2}$ emission and GDP per capita were explained by Environmental Kuznets curve. This study concluded that a monotonic decreasing association among environmental quality and growth in long run. This study revealed that $\mathrm{CO}_{2}$ radiation decreased with increase in GDP per capita.

Awad (2019) investigated that the economic integration had a beneficial or harmful impact on environment in Africa. The panel data during the period of 1990-2017 was used. Environmental quality, GDP per capita, trade openness, income per capita, technology and $\mathrm{CO}_{2}$ emission were the variables of this study. Panel co-integration test and panel unit root were used to estimate the effects of economic integration. This analysis concluded that energy usage had a worsen effect on environment. Thus, overall environmental quality and inter regional trade were collaborative encouraged in Africa.

Safdar et al. (2019) found the influence of energy consumption and environmental degradation on growth in 50 developing countries which are categorized into three income groups, low income, and lower middle income countries for years 1990-2016. By means of PMG-ARDL, the study came to conclusion that energy consumption had positive impact on economic growth in lower middle income and upper middle income countries while in low income countries it had negative impact while environmental degradation had negative impact on economic activities in all three income groups.

Aurangzaib et al., (2020) investigated that how rural and urban population causes $\mathrm{CO} 2$ emission in developing countries over the years 1990-2015. By using fully modified OLS method, the results showed that growth and urban population has positive impact on $\mathrm{CO} 2$ emission while rural population has negative impact on $\mathrm{CO} 2$ emission. Panel causality analysis also identified that economic growth and urbanization are causing environmental degradation in developing countries.

Most of studies concluded that increasing population is burden on economy and causing environmental degradation. Economic growth also causes harmful effect on environment. Cause and effect relationship between growth, population, urbanization and environmental degradation is identified by large number of studies. 


\section{Data and Methodology}

In this part, data and methodological issues are discussed. The variables are explained which are preferable to recognize the influence of environment and population and urbanization on the economic growth.

\subsection{Time Period}

In this analysis the panel data of south Asian developing countries during 2000-2018 is used to check the influence of environment urbanization, and population, on economic growth.

\subsection{Sources of Data}

To see influence of environment, urbanization and population on the economic growth of South Asian Countries, Panel data is collected from "World Development Indicators" (WDI).

\subsection{Selection of Countries}

To analyze the effect of environment, urbanization and population on growth of South Asian Countries which belongs to the low middle income level? The selected South Asian Countries are Bangladesh, India, Nepal, Pakistan and Sri Lanka.

\subsection{Model Specification}

The present study finds the cause and effect of urbanization, total population and environmental degradation and economic growth.

\section{Economic Growth=f (Population, urbanization, $\mathrm{CO} 2$ and capital)}

In the model economic growth used as dependent variable while population urbanization, $\mathrm{CO} 2$ Emission and capital are used as explanatory variables.

$$
\log (\mathrm{GDP})=\alpha \mathrm{O}+\alpha_{1} \log \mathrm{POP} \text { it }+\alpha_{2} \log \mathrm{K} \text { it }+\alpha_{3} \log \mathrm{CO}_{2} \text { it }+\alpha_{4} \log \mathrm{UBN} \text { it }+\mu \text { it }
$$

Where:

Log GDP = log of economic growth

$\log \mathrm{POP}=\log$ of total population.

$\log \mathrm{K}=\log$ of gross capital formation.

$\log \mathrm{CO} 2=\log$ of Carbon Dioxide emission as proxy of Environmental Degradation.

Log UR $=\log$ of Urbanization Population.

\section{Results and Discussion}

\subsection{Cross-sectional Dependence Tests}

To avoid the regional distortions in panel data, cross sectional dependence test is performed firstly on our panel data analysis.

Table 1: Cross-sectional dependence Test Results

\begin{tabular}{|l|l|l|l|l|l|}
\hline Test & GDP & POP & K & UR- pop & CO $_{2}$ \\
\hline Breusch-Pagan LM & $179.98^{* * *}$ & $182.04^{* * *}$ & $168.93^{* * *}$ & $186.78^{* * *}$ & $36.77^{* *}$ \\
\hline Pesran scaled LM & $36.89^{* * *}$ & $37.35^{* * *}$ & $34.42^{* * *}$ & $38.41^{* * *}$ & $4.87^{* * *}$ \\
\hline Bias adjusted LM & $36.75^{* * *}$ & $37.21^{* * *}$ & $34.28^{* *}$ & $38.27^{* * *}$ & $4.73^{* * *}$ \\
\hline
\end{tabular}


Review of Economics and Development Studies, Vol. 6 (4) 2020, 799 - 809

Pesaran CD

$13.41^{*}$

$13.49^{*}$

12.99

$13.67^{*}$

$4.78^{* \star \star}$

\{Notes: ${ }^{*}, * *$, and $* * *$ represent the $10 \%, 5 \%$, and $1 \%$ significance levels, correspondingly.\}

The above table displays cross sectional dependence among the variables. All the variables are significant at $1 \%$. It postulates that variation in one country will be transferred to other countries which reveal importance of joint development policy for these countries.

\subsection{Panel Co-integration}

The panel co-integration test is used in study to examine long run association amongst urbanization, population, economic growth and environmental degradation. This test is beneficial to describe simultaneously long run association among selected variables.

Table 2: Panel Co-integration Results of Dependent and Independent Variables

\begin{tabular}{|l|l|l|}
\hline Assumption & w/o trend & with trend \\
\hline Panel & -1.03 & -1.58 \\
v-statistic & $(0.79)$ & $(0.93)$ \\
\hline Panel & 0.14 & 1.89 \\
rho-statistic & $(0.63)$ & $(0.98)$ \\
\hline Panel & $-1.75^{*}$ & -0.85 \\
PP-statistic & $(0.07)$ & $(0.16)$ \\
\hline Panel & $-0.76^{* *}$ & $-0.88^{* * *}$ \\
ADF-statistic & $(0.05)$ & $(0.00)$ \\
\hline Group & $1.81^{*}$ & 2.89 \\
rho-statistic & $(0.06)$ & $(0.99)$ \\
\hline Group & -1.06 & $-3.07^{* * *}$ \\
PP-statistic & $(0.15)$ & $(0.00)$ \\
\hline Group & $-1.88^{* *}$ & $-2.47^{* *}$ \\
ADF-statistic & $(0.03)$ & $(0.00)$ \\
\hline
\end{tabular}

\{Notes: figures in parentheses are probability values. ***, and *** represent 10\%, 5\%, and $1 \%$ significance level, correspondingly. Number of countries $(\mathrm{N})=5$ and eras $(\mathrm{T})=20$. The maximum numbers of lags were automatically nominated using Akaike information criterion (AIC).\}

The table 2 shows consequences of panel co-integration test. The first column shows the estimated results without trend while the second column results are included trend. The co-integration results showed that three to four out of the seven null hypotheses of no co-integration have been rejected at $1 \%, 5 \%$ and $10 \%$ significance levels. So, model is co-integrated both within the dimension and between dimensions. So, there is indication of long-term association among dependent variable and independent variables in some selected South Asian States.

\subsection{Long Run and Short Run PMG Estimates}

To observe consequence of environmental degradation, urbanization and population on economic growth of South Asian Countries, PMG technique is applied which established long run and short run association amongst all chosen variables. The results are specified in table 3 
Table:3 Long run and Short run PMG Estimates

\begin{tabular}{|c|c|c|c|c|}
\hline \multicolumn{5}{|c|}{ Table 3: PMG Estimates of Model } \\
\hline \multicolumn{5}{|c|}{ Long Run Results } \\
\hline Variable & Coefficient & Std. Error & t-Statistic & Prob.* \\
\hline $\mathrm{LOG} \mathrm{CO}$ & -0.317 & 0.086 & -3.679 & 0.000 \\
\hline LOG K & 0.608 & 0.033 & 18.159 & 0.000 \\
\hline LOG UR-pop & 1.361 & 0.369 & 3.686 & 0.000 \\
\hline LOG POP & -2.948 & 0.705 & -4.184 & 0.000 \\
\hline \multicolumn{5}{|c|}{ Short Run Results } \\
\hline Variable & Coefficient & Std. Error & t-Statistic & Prob.* \\
\hline COINTEQo1 & -0.691 & 0.228 & -3.026 & 0.004 \\
\hline GDP (-1) & 0.124 & 0.159 & 0.779 & 0.440 \\
\hline $\mathrm{CO} 2$ & 0.326 & 0.101 & 3.231 & 0.002 \\
\hline $\mathbf{K}$ & 0.092 & 0.096 & 0.958 & 0.344 \\
\hline$K(-1)$ & -0.116 & 0.106 & -1.095 & 0.280 \\
\hline UR-POP & -104.533 & 76.019 & -1.375 & 0.177 \\
\hline UR-POP (-1) & -206.707 & $213 \cdot 318$ & -0.969 & 0.338 \\
\hline POP & -26.661 & 112.497 & -0.237 & 0.814 \\
\hline POP (-1) & 293.154 & 249.717 & 1.174 & 0.247 \\
\hline C & 20.676 & 7.462 & 2.771 & 0.008 \\
\hline
\end{tabular}

Above table explains long run association among dependent and independent variables through PMG approach. The independent variable environmental degradation as $\mathrm{CO} 2$ emission have -0.317 as coefficient value and the probability value is 0.000 which reveals negative and significant association with growth (GDP). This result indicates that one percent increase in the $\mathrm{CO} 2$ emission will cause of 0.317 percent decrease in growth. This result preview in some previous studies such as Yeh \& Liao (2016), Charfeddine et al. (2018), Adzawala et al. (2016), Bastola \& Sapkota (2015) and Acheampong (2018).

Gross capital formation (K) has 0.608 as coefficient value and the probability value is 0.000 which reveals positive and significant association with growth (GDP). The positive and significant result reveals that one percent rise in gross capital formation will cause of 0.608 percent rise in economic growth (GDP). The positive and significant association has been also discussed in past studies as like Golley \& Wei (2015), Saidi \& Hammami (2018), Bakhsh (2017) and Omri (2013).

The next independent variable is urban population and its coefficient value is 1.360 while probability value is 0.000 which shows the positive and significant relationship with dependent variable economic growth (GDP). This result reveals that one percent increase in population will cause of 1.360 rises in economic growth (GDP). In general, population has positive as well as negative impact on economic growth but according to our analysis, urban population has positive and significant impact on growth. This result also discussed in the previous reviews such as Wang et al. (2018) and Arvin et al. 
(2015).

Finally, total population as an independent variable have -2.947 as coefficient value and the probability value is 0.000 which indicates negative and substantial relationship among economic growth (GDP) and total population. This result exposes that one percent increase in population will cause of 2.947 percent decrease in economic growth. So, all the long run consequences of PMG explain the significant effect of environmental degradation and population on the economic growth of South Asian Countries. From all selected variables gross capital formation and urban population have positive and significant association with economic growth while total population and $\mathrm{CO}_{2}$ emission have negative but significant association with economic growth.

In the short run analysis, results the value of co-integration is -0.691 and value which negative and significant and shows 69 percent adjustment from short run to long run in each year

\subsection{Causality Analysis}

Dumitrescu and Hurlin panel causality test is used to explore the causality amongst different variables. The results of causality analysis are given in following tables:

Table 4: Causality Analysis Results

\begin{tabular}{|c|}
\hline South Asian Countries \\
\hline $\mathrm{K} \leftrightarrow \mathrm{GDP}$ \\
\hline $\mathrm{POP} \leftrightarrow \mathrm{GDP}$ \\
\hline $\mathrm{UR}_{\mathrm{POP}} \rightarrow \mathrm{GDP}$ \\
\hline $\mathrm{CO}_{2} \leftrightarrow \mathrm{GDP}$ \\
\hline $\mathrm{POP} \leftrightarrow \mathrm{K}$ \\
\hline $\mathrm{URPOP}_{\mathrm{PO}} \leftrightarrow \mathrm{K}$ \\
\hline $\mathrm{CO}_{2} \rightarrow \mathrm{K}$ \\
\hline $\mathrm{UR}_{\mathrm{POP}} \leftrightarrow \mathrm{POP}$ \\
\hline $\mathrm{CO}_{2} \leftrightarrow \mathrm{POP}$ \\
\hline $\mathrm{CO}_{2} \leftrightarrow \mathrm{UR}$ POP \\
\hline
\end{tabular}

$\leftrightarrow$ shows the bi-direction causality, $\rightarrow$ shows the uni-direction causality, $\boldsymbol{x}$ shows no causality.

In the above table, it is indicated there is bidirectional causality between all selected variables which shows that all these variables are causing each other.

\section{Policy Implication and Conclusion}

The basic intention of this research is to observe influence of environmental degradation, urbanization and population on economic growth of selected South Asian Countries. The objectives of the study are to observe influence of environmental degradation as $\mathrm{CO}_{2}$ emission on growth of economy and effect of urban and total population on growth of selected countries. The main object is to attain the hypothesis i.e., population and environmental degradation are affecting growth in some selecting South Asian States. The dependent variable of this analysis is economic growth (GDP) while independent variables are $\mathrm{CO}_{2}$ emissions as proxy of environmental degradation, total population (pop), urbanization ( $\mathrm{UR}_{\mathrm{pop}}$ ) and gross capital formation $(\mathrm{K})$. The selecting South Asian Countries consists on Bangladesh, India, Nepal, Pakistan and Sri Lanka.

It is indicated that all the long run consequences of PMG explain the significant effect of environmental degradation and population on the growth of South Asian Countries. From all selected 


\section{Review of Economics and Development Studies, Vol. 6 (4) 2020, 799 - 809}

variables gross capital formation and urban population have positive and significant association with economic growth while total population and $\mathrm{CO} 2$ emission have negative but significant association with economic growth. In the short run analysis, results the value of co-integration is -0.691 and value which negative and significant and shows 69 percent adjustment from short run to long run in each year. The secondary objective of study was to find out cause and effect relationship among selected variables. It is noted by results of panel causality analysis that bidirectional casualty exists among environmental degradation, urbanization, total population and economic growth in selected South Asian countries. The policies suggested by study are as follow:

- The results show that the Carbon Dioxide emissions is main reason of environmental deterioration and harmful for the economic growth (GDP), therefore, Government of South Asian Countries should take steps for reduction in $\mathrm{CO}_{2}$ emission.

- It is necessary to control the population growth and to enhance the economic growth of South Asian Developing Countries, there should be effective population.

- It is necessary that Government should make policies which enhance the gross capital formation (K) for the rapid growth of economy in the South Asian Countries.

- Increase in the urban population cause rise in the economic growth but continuously increase in population may be harmful for the economy. Government should make policies for the betterment of the south Asian countries.

- Bestowing to cross sectional dependency of variables, government of South Asian Countries should make policies through mutually agreement for enhancement of economic growth and reduction in the environmental degradation and population.

\section{References}

Acheampong, A. O. (2018). Economic growth, $\mathrm{CO} 2$ emissions and energy consumption: What causes what and where? Energy Economics, 74, 677-692.

Adzawla, W., Sawaneh, M., \& Yusuf, A. M. (2019). Greenhouse gasses emission and economic growth nexus of sub-Saharan Africa. Scientific African, 3, eooo65.

Ahmad, N., \& Du, L. (2017). Effects of energy production and CO2 emissions on economic growth in Iran: ARDL approach. Energy, 123, 521-537.

Alam, M. M., Murad, M. W., Noman, A. H. M., \& Ozturk, I. (2016). Relationships among carbon emissions, economic growth, energy consumption and population growth: Testing Environmental Kuznets Curve hypothesis for Brazil, China, India and Indonesia. Ecological Indicators, 70, 466-479.

Awad, A. (2019). Does economic integration damage or benefit the environment? Africa's experience. Energy Policy, 132, 991-999.

Bakhsh, K., Rose, S., Ali, M. F., Ahmad, N., \& Shahbaz, M. (2017). Economic growth, CO2 emissions, renewable waste and FDI relation in Pakistan: New evidences from 3SLS. Journal of environmental management, 196, 627-632.

Bélaïd, F., \& Youssef, M. (2017). Environmental degradation, renewable and non-renewable electricity consumption, and economic growth: Assessing the evidence from Algeria. Energy Policy, 102, 277-287.

Botetzagias, I., Tsagkari, M., \& Malesios, C. (2018). Is the 'Troika'Bad for the Environment? An Analysis of EU Countries' Environmental Performance in Times of Economic Downturn and Austerity Memoranda. Ecological Economics, 150, 34-51.

Charfeddine, L., Al-Malk, A. Y., \& Al Korbi, K. (2018). Is it possible to improve environmental quality without reducing economic growth: Evidence from the Qatar economy? Renewable and Sustainable Energy Reviews, 82, 25-39. 
Review of Economics and Development Studies, Vol. 6 (4) 2020, 799 - 809

Chen, J., Zhou, C., Wang, S., \& Li, S. (2018). Impacts of energy consumption structure, energy intensity, economic growth, urbanization on PM2. 5 concentrations in countries globally. Applied energy, 230, 94-105.

Farooq, F., Gardezi, M. A., \& Safdar, N. (2020). How do Population and Poverty Affect Environmental Degradation in Developing Countries? A Panel Data Analysis. Review of Applied Management \& Social Science, 3(1), 85-98

Gilmont, M., Hall, J. W., Grey, D., Dadson, S. J., Abele, S., \& Simpson, M. (2018). Analysis of the relationship between rainfall and economic growth in Indian states. Global environmental change, 49, 56-72.

Hanif, I., \& Gago-de-Santos, P. (2017). The importance of population control and macroeconomic stability to reducing environmental degradation: an empirical test of the environmental Kuznets curve for developing countries. Environmental Development, 23, 1-9.

Lin, S., Wang, S., Marinova, D., Zhao, D., \& Hong, J. (2017). Impacts of urbanization and real economic development on $\mathrm{CO} 2$ emissions in non-high income countries: Empirical research based on the extended STIRPAT model. Journal of cleaner production, 166, 952-966.

Liobikienè, G., \& Butkus, M. (2018). The challenges and opportunities of climate change policy under different stages of economic development. Science of the total environment, 642, 999-1007.

Mahmoud, S. H., \& Gan, T. Y. (2018). Long-term impact of rapid urbanization on urban climate and human thermal comfort in hot-arid environment. Building and Environment, 142, 83100.

Miao, L. (2017). Examining the impact factors of urban residential energy consumption and $\mathrm{CO} 2$ emissions in China-Evidence from city-level data. Ecological indicators, 73, 29-37.

Mikayilov, J. I., Galeotti, M., \& Hasanov, F. J. (2018). The impact of economic growth on CO2 emissions in Azerbaijan. Journal of cleaner production, 197, 1558-1572.

Moutinho, V., Varum, C., \& Madaleno, M. (2017). How economic growth affects emissions? An investigation of the environmental Kuznets curve in Portuguese and Spanish economic activity sectors. Energy Policy, 106, 326-344.

Safdar, N. (2020). How do Energy Consumption, Environmental Degradation and Macroeconomic Performance Cause in Developing Countries? An Analysis. Journal of Business and Social Review in Emerging Economies, 6(3).

Safdar, N., Chaudhry, I. S., \& Chaudhry, M. O. (2019). Energy Consumption, Environmental Degradation and Economic Growth in Developing Countries. Pakistan Journal of Social Sciences (PJSS), 39(2).

Wang, Q., Su, M., \& Li, R. (2018). Toward to economic growth without emission growth: The role of urbanization and industrialization in China and India. Journal of cleaner production, 205, 499-511.

Yeh, J. C., \& Liao, C. H. (2017). Impact of population and economic growth on carbon emissions in Taiwan using an analytic tool STIRPAT. Sustainable Environment Research, 27(1), 41-48. 